\title{
EXPERIMENTAL INVESTIGATION ON FLOW PROPERTIES OF MUSKMELON PULP USING CONTROLLED STRESS RHEOMETER
}

\author{
D. RAMESH BABU ${ }^{*}$, P. ISSAC PRASAD ${ }^{2}$, S. JAGAN MOHAN RAO ${ }^{3} \&$ K. V. NARASIMHA RAO ${ }^{4}$ \\ ${ }^{1 *}$ Scholar, Department of Mechanical Engineering, Koneru Lakshmaiah Education Foundation, Green Fields, \\ Vaddeswaram, Guntur District, Andhra Pradesh, India \\ ${ }^{2,4}$ Professor, Department of Mechanical Engineering, Koneru Lakshmaiah Education Foundation, Green Fields, \\ Vaddeswaram, Guntur District, Andhra Pradesh, India \\ ${ }^{3}$ Professor, Department of ECE, Ramachandra College of Engineering, Eluru, Andhra Pradesh, India
}

An experimental study was conducted on muskmelon fruit pulp using a controlled stress Rheometer. The flow behavior, Consistency index is calculated using the flow data of shear stress and shear strain. The pulp behaved thixotropic in nature. Three models are used to explain the flow behavior, viz. Casson, Ostwald and Herschel-Bulkley. Mathematical modeling of data from the curve of Shear Stress Vs Shear rate indicated that Herschel-Bulkley model fitted the best with correlation coefficient of 0.99. The stress required to indicate viscous nature is found to be $3.3 \mathrm{~Pa}$ as per Casson model, which precisely indicates the stress required to initiate flow. This behavior appears same as tomato ketchup or sauce flow from the thermally processed glass bottles. The thixotropic loop experiment has confirmed the solid nature of the pulp with a residual stress of 3.1 Pa. This data is useful to design equipment for thermal treatment of fruit pulp, fluid flow in heat exchangers of food processing lines and further reference studies of flow behavior of different fruit pulps.

KEYWORDS: Muskmelon Pulp, Flow Properties, Shear Stress, Shear Strain, Thixotropic Behavior \& Controlled Stress Rheometer
\end{abstract}

Received: May 17, 2020; Accepted: Jun 07, 2020; Published: Jul 29, 2020; Paper Id.: IJMPERDJUN2020510

\section{INTRODUCTION}

Fruit pulps are used for several preparations like Ketchup, Sauce, Jam, Jelly, Nectar, Juice, Concentrated pulp for secondary processing, etc. Muskmelon fruit is found to be an underutilized fruit in terms of processing. Tomato, Apple, Orange, Mango are popular among fruit juices, nectar and other processed items sold in the market.

Muskmelon is a spherical fruit with hard peel and yellowish pulp for the varieties grown in India. Muskmelon pulp can be used as an ingredient for baby foods or any other secondary food preparations.

High moisture content of this fruit indicates viscous nature in bulk when made into pulp. However, some studies indicate that fruit pulps are of both viscous and elastic nature inherently. To initiate flow from the stagnant semi-solid pulp, some minimum stress is required. This is predominantly can be observed when using ketchup or sauce from a bottle or any packing having a narrow opening. When a bottle of sauce is tilted for withdrawing little quantity, a little force is required to take out the material from the bottle. This can be termed as elastic nature subsided with the visco-elastic fruit pulp. 
Viscosity is always a measure of temperature. Processing and preservation of pulps are done in a wide range. During fresh fruit storage a temperature range of $0-5{ }^{\circ} \mathrm{C}$ are used. Fruit/pulp is exposed to $15-25^{\circ} \mathrm{C}$ during peeling, slicing and pulping. Pulps are thermally treated at $100^{\circ} \mathrm{C}$ to $105^{\circ} \mathrm{C}$, in case of retort or thermal processing and preservation.

Bulk 200 Liter drums are used for preserving either pulp or processed fruit mix for secondary packing or preparations. The drums are stored at $5-7^{\circ} \mathrm{C}$ in cold rooms until consumption.

The final packing in retail pouches or glass bottles make them preserved at room temperature. Ultimate user may use the ketchup or sauce of pulp at room temperature. So studying the flow properties is necessary to design equipment during processing operations.

During peeling, slicing and pulping, addition of pectin during processing of fruit pulps improves the texture in terms of reducing viscosity, thereby improving consistency apart from other benefits of preservation. However, viscous nature dominates within the bulk visco-elastic fluid.

\section{LITERATURE OVERVIEW}

Fluid foods behave viscous in nature at certain temperatures. Food like ice creams and shortenings will have solid properties at frozen temperatures [1]. Flow behavior of a Turkish fermented beverage "boza" was reported by Mahmut et al. 2002 [2].

Sato et al. (2009) reported the jaboticaba pulp viscosity and flow properties. They have correlated the properties to the particle size. They have reported about the minimum stress requirement to initiate the flow [3].

Several researchers reported the viscous and visco-elastic nature of fruit pulps especially when texturized with gelling agents [4-6]. Alginates improve the texture and impart solid properties when added to the fruit pulps.

Augusto et al. (2012) reported the effect of temperature on rheological properties of siriguela pulp. Temperature increase reduced the viscosity [7].

Manjunatha et al. (2012) studied the rheological behavior of lime juice concentrate and reported the effect of temperature, Total Soluble Solids content on the flow behavior. Using controlled stress Rheometer, they have fitted the data to the mathematical models. Effect of Temperature was explained using Arrhenius relationship. Rate constants were calculated [8].

Behavior of pineapple milk and lassi during spray drying was reported by Ramesh Babu and Das Gupta (2006). They studied the compressibility, free and packed density, shelf life with sensory properties. Pineapple and milk, lassi combinations yielded to shelf stable products which were used for the consumption of defense forces. Products were in highly acceptable condition till six months with an overall acceptability of seven and above on the nine point hedonic scale [9].

Preservation of fruit products using cooling were studied and reported in terms of refrigeration systems, ripening process, thermal insulation and system requirements for mango and banana[10] and Kinnow fruits[11].

Cooling preservation of different fruits like Banana (Narasimha Rao et al), Mango (Narasimha Rao et al), and apples are reported. For apples the low oxygen and high carbon dioxide works as combination preservation apart from cooling alone. Low oxygen keeps respiration low. High RH keeps humid and less moisture loss from the fruit and Low 
temperature reduces the physiological processes of ripening [12-15].

The objective of this investigation is to find the minimum stress required to initiate flow within the semi-solid fruit pulp made of muskmelon. Thixotropic behavior and multiple loop experiments were used to find the plastic nature of visco-elastic muskmelon-pulp.

\section{MATERIALS AND METHODS}

Muskmelon was procured from the local market of Mysore. After a chlorine surface de-contamination, the fruits are peeled using a mechanical peeler (M/s Continental Equipment, Bangalore), then sliced into $4 \mathrm{~mm} \times 4 \mathrm{~mm}$ cross section slices using a Slicer (Supplied by M/s Urschell, USA). The slices are converted into pulp using a pulper. The pulp is preserved in PE film packing in a cold room at $5^{0} \mathrm{C}$ till the experiments are completed.

Controlled Stress Rheometer experiments: ParPhysica make Rheometer is used for conducting experiments on flow behavior. Cup and cone arrangement is used for testing of pulp. Instrument room is maintained at $26 \pm 1^{\circ} \mathrm{C}$ during experimentation. Temperature of the sample is controlled by a temperature water bath supplied along with the instrument. Sample temperature is maintained at $25^{\circ} \mathrm{C} \pm 0.1^{\circ} \mathrm{C}$.

Each experiment is carried for six times and the average values are reported. Statistical analysis and mathematical modeling is done using the software provided with the instrument Par-physica (Make: Anton Par).

- Power law equation (Ostwald): $\sigma=\mathrm{k} \ddot{\mathrm{Y} n}$

$\ddot{Y}$ is shear rate $\left(\operatorname{Sec}^{-1}\right)$,

$\sigma$ is shear stress $\left(\mathrm{N} / \mathrm{m}^{2}\right)$,

$\mathrm{K}$ is Consistency index $\left(\mathrm{N} \mathrm{Sec} / \mathrm{m}^{2}\right)$,

" $n "$ is flow behavior index.

- Casson equation: $\sigma^{0.5}=\mathrm{Koc}+(\mathrm{Kc})^{\text {Ÿ0.5 }}$

$\mathrm{Koc}^{2}$ is Yield stress

- Herschel-Bulkley equation: $\sigma=\sigma o+\mathrm{Kh} \ddot{Y} \mathrm{n}$

$\mathrm{Kc}$ and $\mathrm{Kh}$ are constants

бo is yield stress

\section{RESULTS AND DISCUSSIONS}

Shear stress and shear rate curve shown in Figure 1 indicates the flow behavior of the muskmelon pulp. Shear rate resulted in non-linear positive change in shear stress. Shear rate was applied from 0-1500/s, which result shear stress up to 14Pa. The data was fitted to three different viscosity flow models, viz. Power law (Ostwald), Casson and Herschel-Bulkley. Relevant consistency coefficients are calculated along with correlation coefficients which are presented in figure 1. 


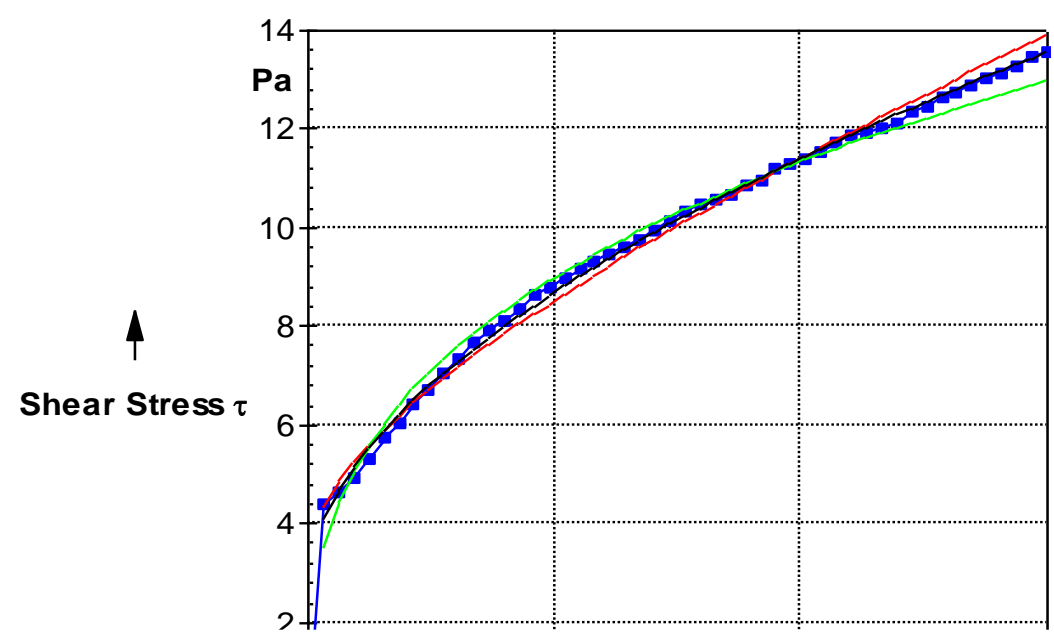

Figure 1: Predicted Vs Experimental Values of Shear Stress against

Shear Rate on Muskmelon Pulp at $25^{\circ} \mathrm{C}$.

Another test was conducted with constant shear rate with respect to time. Test is conducted at 50, 200, 500, 1000/s. Thixograms are shown in figure 3.Analysis indicates higher shear rates at higher shear stresses.

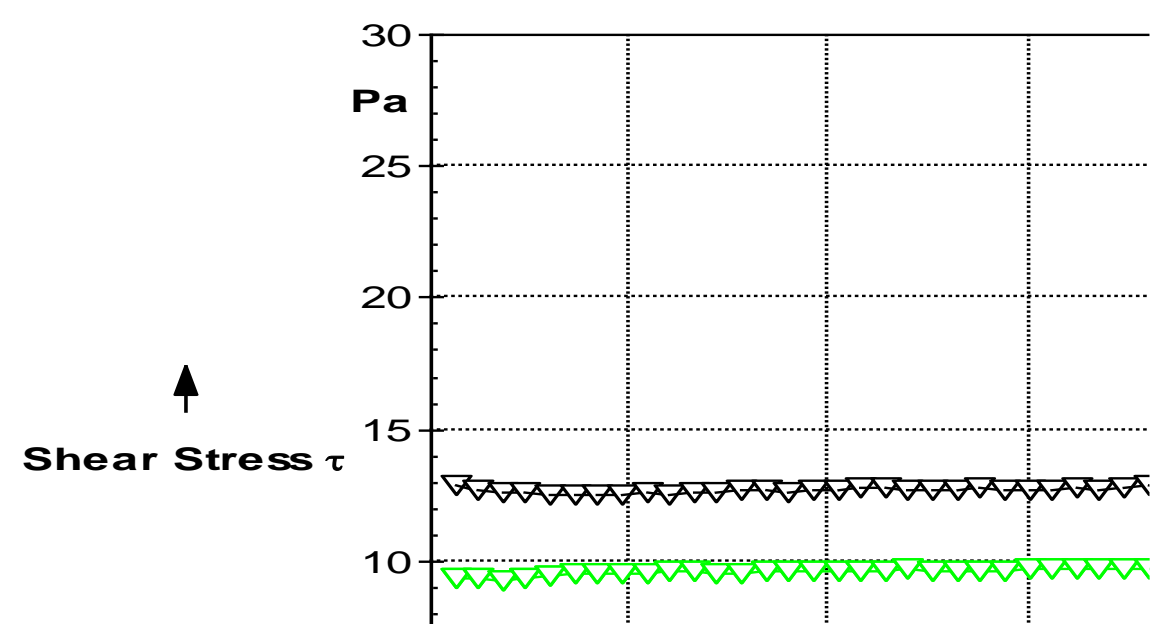

Figure 2: Constant Shear Rate Test on Muskmelon Pulp from 0-300 Seconds.

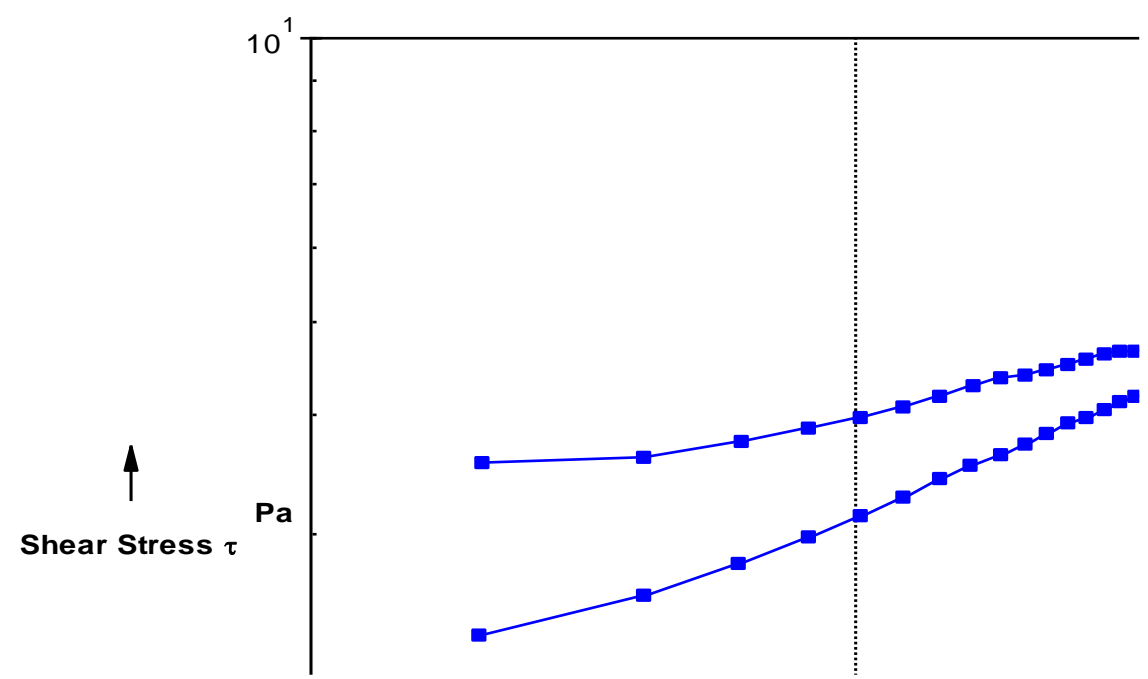

Figure 3: Thixotropic Loop Test for Muskmelon Pulp. 
The resistance to flow within the small zone of plasticity is measured using thixotropic loop test as shown in Figure 3. Shear rate was applied from $0-10 / \mathrm{s}$ and reversed from 10/s up to lowest measurable value. In the forward shear rate a stress of $2.0 \mathrm{~Pa}$ is observed and during backward shear rate application a residual stress of $3.1 \mathrm{~Pa}$ recorded. The thixotropic loop indicates the energy stored within the pulp when stress is relaxed.

The flow behavior results are similar in nature when compared to the experimental results of lime juice as reported by Manjunatha et al. However they have studied the enzyme clarified juice, so the viscosity values are much lower than that of muskmelon pulp reported here. This may be due to high soluble solids in muskmelon pulp. However they did not do the thixotropic loop test to find the yield stress.

\section{CONCLUSIONS}

Flow properties of muskmelon pulp are measured experimentally at controlled temperature of $25^{\circ} \mathrm{C}$ using a controlled stress Rheometer. Flow properties in terms of shear stress, shear rate and consistency index are mathematically predicted by fitting the data to three well established models, viz. Casson, Ostwald and Herschel - Bulkley. Highest correlation coefficient of 0.99 is found with Herschel-Bulkley model. Shear stress- shear rate and thixotropic loop tests resulted in determining the minimum stress required flow above which viscous behavior observed. Plastic flow subsided within viscous flow has been confirmed from thixotropic loop experiment. Semi-solid nature of the pulp behaves viscous in bulk; however, little stress is required to initiate flow. 3.1 to $2.0 \mathrm{~Pa}$ is the minimum stress required, which may be correlated to the requirement of bottled sauce/pulp/ketchup fruit or vegetable products. These results can be useful for designing the heat exchangers for fruit juice processing and any other thermal treatment equipment having flow requirements for muskmelon processing.

\section{ACKNOWLEDGEMENT}

The authors thank Dr A S Bawa, Director (Retd) and Sh D K Das Gupta -Scientist- Fruits and Vegetables Technology (Retd) for DFRL-DRDO for their encouragement for experimental studies and permission for publishing this work.

\section{REFERENCES}

1. Rao, M. A. "Rheological properties of fluid foods." Engineering properties of foods (1986): 1-47.

2. Genç,Mahmut, Murat Zorba, and Gülden Ova. "Determination of rheological properties of boza by using physical and sensory analysis." Journal of Food Engineering 52.1 (2002): 95-98.

3. Mahto, Vikas, and Harveer Singh. "Effect of Temperature and Pour Point Depressant on the Rheology of Indian Waxy Crude Oil." International Journal of General Engineering and Technology (2013).

4. Sato, Ana Carla K., and Rosiane L. Cunha. "Effect of particle size on rheological properties of jaboticaba pulp." Journal of Food Engineering 91.4 (2009): 566-570.

5. Mancini, M., Moresi, M. and Rancini, R. (1999). Uniaxial compression and stress relaxation tests on alginate gels. Journal of Texture Studies. 30, 639-657.

6. Bhambri, P. A. L. L. A. V. I., and B. R. I. A. N. Fleck. "Drag Reduction using high molecular weight polymers in TaylorCouette Flow." Int. J. Mech. Prod. Eng. Res. Dev 6 (2016): 59-72.

7. Mouquet, C., Dumas, J. C. and Guilbert, S. (1992). Texturization of sweetened mango pulp, optimization using response surface methodology. Journal of Food Science. 57, (6), 1395-1400. 
8. Nussinovitch, A. and Peleg, M. (1990). Mechanical properties of raspberry product texturized with alginates. Journal of Food Processing \& Preservation. 14, 267-278.

9. Augusto, Pedro ED, Marcelo Cristianini and Albert Ibarz. "Effect of temperature on dynamic and steady-state shear rheological properties of siriguela (Spondias purpurea L.) pulp." Journal of Food Engineering 108.2 (2012): 283-289.

10. Yadav, Upendra Singh, and V. I. K. A. S. Mahto. "Rheological Investigations of Partially Hydrolyzed PolyacrylamideHexamine-Hydroquinone Gels." International Journal of Chemical \& Petrochemical Technology 3.3 (2013): 9-16.

11. Manjunatha, Shringari Subramanyaiah, Pakalapati Srinivasa Raju, and Amrindar Singh Bawa. "Modelling the rheological behaviour of enzyme clarified lime (Citrus aurantifolia L.) juice concentrate." Czech Journal of Food Sciences 30.5 (2012): 456-466.

12. D Ramesh Babu and Das Gupta, DK (2005) Development Of Pineapple Juice-Milk/Lassi Powders, Journal Of Food Science And Technology-Mysore, 42(3)241-245.

13. Mahto, V. I. K. A. S., and A. J. A. Y. Kumar. "Effect of several parameters on wax deposition in the flow line due to Indian waxy crude oil." Int J Appl Eng Res Dev 3.4 (2013): 1-10.

14. D Ramesh Babu, K. V. Narasimha Rao \& Syam Kolati (2019) The Design Of Refrigeration, Thermal Insulation And An Equipment For Healthy Ripening Of Mango And Banana Without Using Harmful Chemicals, International Journal of Mechanical and Production Engineering Research and Development (IJMPERD) ISSN(P): 2249-6890; ISSN(E): 2249-8001, Vol. 9, Issue 1, Feb 2019, 423-434.

15. D Raghava Kumari, D Ramesh Babu and K V Narasimha Rao (2020), Mathematical modeling of temperature profiles during un-steady cooling of fruits stored in a cold store unit, International Journal of Advanced Science and Technology, Vol. 29, No. 4, (2020), pp. $5894-5900$.

16. Ram Deshmukh, D Ramesh Babu and K V Narasimha Rao., "Pressure Testing Results (As A Decision Tool For Deciding Low Oxygen Or Ultra-Low Oxygen Or High Oxygen Storage) Of Semi-Hermetically Sealed Controlled Atmosphere Storage Insulated Chambers". IJMPERD, (2020), vol.10, no.1, pp. 531-540.

17. Narasimha Rao K V, Shareef Shaik and Ramesh Babu. D, "Mathematical Modeling of Cooling Rates of Mango Fruits During Unsteady State Cooling in An Artificial Ripening Chamber”, Test Engineering and Management, (2020), March-April, vol 83, pp.6862-6871.

18. Narasimha Rao K V, Sasank Devarakonda and Ramesh Babu D, "Mathematical Modeling of Cooling Rates of Mango Fruits During Unsteady State Cooling in An Artificial Ripening Chamber”, Test Engineering and Management, (2020), March-April, vol 83, pp.6872-6879.

19. D. Ramesh Babu, K. V. Narasimha Rao, M. V. Satish Kumar \& B. Satish Kumar (2018), Handling of apples during sortinggrading operation and measuring the mechanical properties firmness after controlled atmosphere storage International Journal of Mechanical and Production Engineering Research and Development Vol. 8, Issue 6, Dec 2018,617-634 


\section{AUTHORS PROFILE}

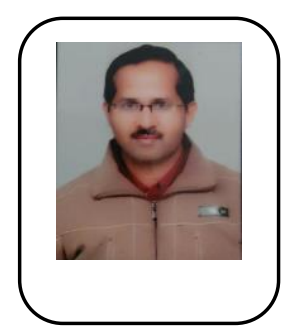

D. Ramesh Babu has got over 24 years of professional experience in manufacturing, research, maintenance, consultancy and project management of Refrigeration, Cold Storage and Controlled Atmosphere storage technologies.

He was graduated in Mechanical Engineering from JNTU College of Engineering, Hyderabad in the year 2000 and obtained MBA in production and operations management from MDU,Rohtak. He also obtained his MTech in Advanced Manufacturing from JNTU, Hyderabad. He has got expertise in refrigeration, fruit preservation and food processing. He is presently working as Assistant Professor in Mechanical Engineering at S R Engineering college, Warangal since year 2014. He has four years of experience in refrigeration equipment manufacturing at Voltas Limited, seven years of experience in fruit preservation at Defence food research laboratory, DRDO-Mysore and worked for eight years at cold chain project of CONCOR before joining teaching.

He is a recipient of DRDO cash award in the year 2003. He was nominated by CONCOR for eight days visit to ISRAEL as part of cold chain project for preservation of apples in the year 2011. He has published 4 research papers in SCI indexed journal, 15 papers in SCOPUS indexed journals and 6 in ICI indexed journals. He also presented numerous papers at various International and national conferences. His paper got best paper award by the TJPRC for the paper on "The Design of Refrigeration, Thermal Insulation and an Equipment for Healthy Ripening of Mango and Banana without Using Harmful Chemicals." published in IJMPERD.

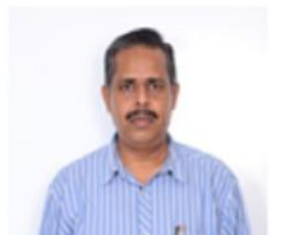

Dr P. Issac Prasad, has 22 years of experience and working as Professor in the Department of Mechanical Engineering, KLEF (Deemed to be University), Vaddeswaram. He obtained Doctoral degree from JNTUA in the field of Thermal Engineering. He acted as Thermal Engineering Research Group head in the Department of Mechanical Engineering, KLEF. He worked as Principal at two Engineering Institutions affiliated to JNTUK and JNTUA. Apart from conference, national and international publications, at present he is also acting as Associate Dean - IQAC, KLEF. 


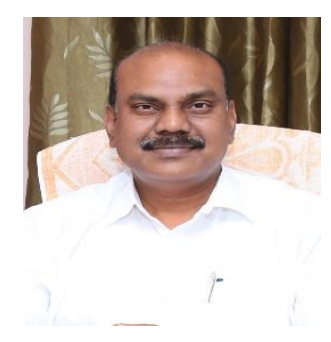

Dr S Jagan Mohan Rao has 29 years of work experience in teaching, research (Active power control of submerged arc furnaces for the production of Ferro-chrome and Ferro-silicon, and, Control of steam bus for 2 turbines) and industry (Power sector and Ferro alloys). Expertise in tailoring of Distributed Control Systems, Programmable Logic Controllers and SCADA systems.

He is Presently working as professor of ECE in Ramachandra College of Engineering, Eluru (Andhra Pradesh). Trainings had in DCS, Power medicine and fire fighting.

Projects: MODROB 2019 with an advance of Rs. 1286400.

IEDC projects at College: 2.

Memberships: ISTE, IETE and IE.

Patents: Industrial Design (Parabolic Trough Collector) - Application no.: 329700-001 dt 30.05.20

ADD-ON COURSES TAUGHT:PLC Programming and Design of PCBs

PAPER PUBLICATIONS:About 20 plus papers

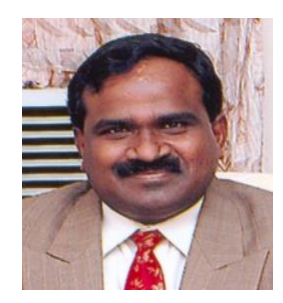

Dr K V Narasimha Rao is a senior Professor with 27+ years experience in Academic, Consultancy and Industry and has been working with KLEF (Deemed to be University) Vaddeswaram since 2 September 2016. Dr Narasimha Rao was graduated in Mechanical Engineering from Regional Engineering College, Warangal in 1986 and went on to obtain Master's and Doctoral degrees from the Indian Institute of Science, Bangalore during 1990 and 1995 respectively in the field of Thermal Engineering. He worked for seven years (1995-2002) as Research Associate and Fellow, Industrial Energy Group at Tata Energy Research Institute (teri), Southern Regional Centre, Bangalore before moving into Academics in 2002. Prior to joining KLEF, he worked at few Engineering Colleges as Principal/Director/Dean. Dr Rao has published 40 scientific papers (three in SCI Listed Journals, 30 Scopus indexed Journals and Chapter 10 in Recent Advances in Material Sciences, Lecture Notes on Multidisciplinary Industrial Engineering) and numerous technical reports for various National/International Agencies. HE has filed 14 patents (three published).

\section{Membership of Professional Bodies}

Dr Rao is a member of ASHRAE, ISCA, ISHMT, ISHRAE, ISTE \& SESI and Fellow of Institution of Engineers (India). 


\section{Scholarships \& Awards}

- Recipient of 'National Merit Scholarship' during 1980-85 (6 Years).

- Recipient of 'Special Rank' in Mathematics Olympiad conducted by Andhra Pradesh Association of Mathematics Teachers (APAMT), Hyderabad, A. P. at Senior Level during 1980-81.

\section{Areas of Specialization}

- Energy Auditing, Energy Conservation \& Management, Heat Transfer, Refrigeration \& Air-conditioning and Renewable Energy Sources.

\section{Research Guidance}

Supervised 14 M. Tech. Students and presently guiding Six PhD Scholars and four M. Tech. Students.

\section{Important Projects Handled}

- Dr Rao was the Team Leader for the Consultancy Assignment on Energy Efficiency Services-Phase-III (3 May30 November 1998), for the Ministry of Industry, His Majesty's Govt. of Nepal, Industrial Energy Management Component of the Power Sector Efficiency Project (PSEP) - IDA Credit No. 2347-NEP, World Bank. The activities included Demand Side Management (DSM), Furnace \& Kiln and Boiler Efficiency studies, Cogeneration Feasibility studies covering 65 major industries in Nepal. Trained 11 Nepalese Engineers as Certified Energy Auditors as part of the Consultancy Assignment.

- Dr Rao was involved in the field-testing of a number of Energy Saving Devices / Retrofits under the Energy Saving Demonstration Project, funded by GTZ, Germany.

- Dr Rao has developed and Demonstrated "Performance Contract for Industrial Energy Management" for Indian Scenario, sponsored by Canadian International Development Agency. 
